\title{
CPW Fed Miniaturized UWB Tri-Notch Antenna with Bandwidth Enhancement
}

\author{
MuhibUr Rahman \\ Department of Electrical Engineering, College of Signals, National University of Sciences and Technology, \\ Islamabad, Pakistan \\ Correspondence should be addressed to MuhibUr Rahman; muhib462@yahoo.com
}

Received 28 July 2016; Accepted 18 September 2016

Academic Editor: Sarod Yatawatta

Copyright (C) 2016 MuhibUr Rahman. This is an open access article distributed under the Creative Commons Attribution License, which permits unrestricted use, distribution, and reproduction in any medium, provided the original work is properly cited.

\begin{abstract}
A Coplanar Waveguide (CPW) fed miniaturized ultra-wideband (UWB) tri-notch antenna with bandwidth enhancement is proposed. The antenna is prototyped for ultra-wideband (UWB) communication applications with bandwidth enhancement. By implementing asymmetric structure, the miniaturization in the antenna has been achieved with a very compact size of $22 \times 13$ $\times 1.5 \mathrm{~mm}^{3}$ making it suitable for USB dongle applications. The antenna is first simulated with partial rectangular ground plane which shows that operating bandwidth ranges from 3.1 to $10.6 \mathrm{GHz}$. Then the antenna is measured and simulated by cutting the ground plane with specific geometry which shows that operating bandwidth now ranges from 3.1 to $20 \mathrm{GHz}$ which provides a wide usable fractional bandwidth of more than $150 \%$. The antenna is then modified for tri-notch applications in order to reject worldwide interoperability for microwave access (WiMAX) band (3.3-3.6 GHz) and wireless local area network (WLAN) frequency bands (lower WLAN (5.15-5.325) and upper WLAN (5.725-5.825) GHz). Triple Band rejection capability has been achieved by introducing three complementary split ring resonators (CSRR) in the radiating patch.
\end{abstract}

\section{Introduction}

Coplanar Waveguide (CPW) fed monopole antennas have been extensively used for the design of wireless ultrawideband (UWB) communication systems due to their specific advantages of low cost, simple structure, and omnidirectional radiation pattern. As the FCC allocated the frequency spectrum of 3.1-10.6 GHz for UWB communication applications, the design of UWB antennas has been major research topic among the researchers.

There are several important challenges that need to overcome while designing UWB antenna such as miniature size, acceptable gain, wide impedance bandwidth, stable radiation pattern, and interferences due to other existing technologies. As 3.3-3.6 GHz frequency band has been allocated for worldwide interoperability for microwave access (WiMAX) and 5-6 GHz frequency band has been reserved for wireless local area network (WLAN). The WLAN further comprises two narrow frequency bands including lower WLAN (5.150$5.350 \mathrm{GHz})$ and upper WLAN $(5.725-5.825 \mathrm{GHz})$. These high power narrow frequency bands within the UWB spectrum generate a jamming effect on UWB systems because of electromagnetic interference which can be mitigated by designing UWB antenna that has multiple band rejection capabilities.

To obtain band rejection capabilities filters may also be used, but implementing filters increases the complexity as well as size of the system. Therefore, UWB antenna with band rejection capabilities is the most suitable and economic solution of this problem. Various antennas with band rejection capabilities have been proposed in the literature [1-5]. The common practice to achieve band rejection capabilities is to etch different types of slots such as $\mathrm{H}$-shaped, C-shaped, and $\mathrm{U}$-shaped in the radiating patch of UWB antenna [1-4]. Furthermore antennas with dual band rejection capabilities have been proposed in the literature $[4,5]$. 
Bandwidth enhancement of UWB antenna is also one of the latest topics of research nowadays. The printed monopole dual notched UWB antenna with bandwidth enhancement is suggested in [6]. The designed antenna operates from 2.2 $\mathrm{GHz}$ to $13.4 \mathrm{GHz}$ having two notched bands at WiMAX and WLAN frequency bands. The improved performance of impedance bandwidth is almost $130 \%$. Also compact dual notched UWB antenna with bandwidth dispensation is proposed in [7]. The designed antenna operates from $2.71 \mathrm{GHz}$ to $12.06 \mathrm{GHz}$ having two notched bands at WiMAX and WLAN frequency bands. The bandwidth dispensation is done by inserting an inverted T-shaped slot resonator in the radiating patch. Nearly $125 \%$ bandwidth improvement is done by the presented technique. Likewise, the monopole UWB antenna with enhanced bandwidth capability is presented in [8]. The antenna designed consists of square radiating patch and ground plane with a pair of rotated slots and parasitic structures. The designed antenna operates from $3.06 \mathrm{GHz}$ to $18.3 \mathrm{GHz}$. In [8] bandwidth enhancement is up to $140 \%$ without removing high power interfering bands in UWB. Therefore, an efficient bandwidth enhancement along with band-notching technique is still a difficult task to implement.

In this paper, we firstly present a miniaturized reference UWB antenna operating from 3.1 to $10.6 \mathrm{GHz}$. Then the antenna is measured and simulated by cutting the ground plane with specific geometry which shows that operating bandwidth now ranges from 3.1 to $20 \mathrm{GHz}$ with a wide usable fractional bandwidth of $150 \%$. This antenna is fabricated on FR4 substrate with $\varepsilon_{r}=5.4$. The total size of the antenna is 22 $\times 13 \times 1.5 \mathrm{~mm}^{3}$, which makes it a good candidate for portable UWB communication applications. Measured and simulated results show that the proposed antenna could cover the whole UWB frequency band from 3.1 to $10.6 \mathrm{GHz}$ with bandwidth enhancement which ranges from $10.6 \mathrm{GHz}$ to $20 \mathrm{GHz}$.

Also a proposed miniaturized UWB antenna with triple band rejection capabilities is successfully designed by introducing three complementary split rings resonators (CSRR) in the radiating patch. The simulated VSWR show that the proposed antenna operates in the overall UWB frequency band with VSWR less than 2, except the rejected bands at 3.3-3.6 GHz, 5.1-5.35 GHz, and 5.7-5.95 GHz for filtering the WiMAX, lower WLAN, and upper WLAN frequency bands, respectively. Simulated radiation patterns and surface current distributions are also given, and stable radiation patterns are observed. Table 1 shows the superiority of proposed miniaturized UWB antenna over the recently proposed UWB antennas.

\section{Antenna Geometry}

The geometry of the reference miniaturized UWB antenna, bandwidth enhanced miniaturized UWB antenna, and bandwidth enhanced miniaturized tri-notch UWB antenna are given in Figure 1, and the parameters are optimized using CST Microwave Studio Suite. The antenna is fabricated on FR4 substrate with $\varepsilon_{r}=5.4$ and the length and width of substrate are $L_{\text {sub }}=22 \mathrm{~mm}$ and $W_{\text {sub }}=13 \mathrm{~mm}$, respectively. Detailed
TABLE 1: Comparison between presented and recently reported UWB antennas.

\begin{tabular}{lcc}
\hline Literature & Pass band & Dimensions \\
\hline$[9]$ & 3.5 to $12 \mathrm{GHz}$ & $28 \mathrm{~mm} \times 24 \mathrm{~mm} \times 1.6 \mathrm{~mm}$ \\
{$[10]$} & 3 to $10.6 \mathrm{GHz}$ & $26 \mathrm{~mm} \times 24 \mathrm{~mm} \times 1.6 \mathrm{~mm}$ \\
{$[11]$} & 1.08 to $27.4 \mathrm{GHz}$ & $124 \mathrm{~mm} \times 120 \mathrm{~mm} \times 1.5 \mathrm{~mm}$ \\
{$[12]$} & 3.5 to $31.9 \mathrm{GHz}$ & $35 \mathrm{~mm} \times 30 \mathrm{~mm} \times 0.8 \mathrm{~mm}$ \\
{$[13]$} & 3 to $11 \mathrm{GHz}$ & $30 \mathrm{~mm} \times 36 \mathrm{~mm} \times 1.5 \mathrm{~mm}$ \\
{$[14]$} & 3.1 to $11.45 \mathrm{GHz}$ & $28 \mathrm{~mm} \times 14.5 \mathrm{~mm} \times 0.8 \mathrm{~mm}$ \\
{$[15]$} & 3 to $11.2 \mathrm{GHz}$ & $44 \mathrm{~mm} \times 49.5 \mathrm{~mm} \times 1.5 \mathrm{~mm}$ \\
{$[16]$} & 2.82 to $13.95 \mathrm{GHz}$ & $30 \mathrm{~mm} \times 36 \mathrm{~mm} \times 0.4 \mathrm{~mm}$ \\
{$[17]$} & 3.1 to $11 \mathrm{GHz}$ & $32 \mathrm{~mm} \times 28 \mathrm{~mm} \times 1.5 \mathrm{~mm}$ \\
{$[18]$} & 3.04 to $10.87 \mathrm{GHz}$ & $20 \mathrm{~mm} \times 20 \mathrm{~mm} \times 1.5 \mathrm{~mm}$ \\
{$[19]$} & 3.1 to $12 \mathrm{GHz}$ & $24 \mathrm{~mm} \times 30 \mathrm{~mm} \times 1.6 \mathrm{~mm}$ \\
{$[20]$} & 3.4 to $10.3 \mathrm{GHz}$ & $24 \mathrm{~mm} \times 16 \mathrm{~mm} \times 1.5 \mathrm{~mm}$ \\
{$[21]$} & 3.2 to $14.4 \mathrm{GHz}$ & $31 \mathrm{~mm} \times 22 \mathrm{~mm} \times 0.8 \mathrm{~mm}$ \\
{$[22]$} & 3.08 to $12.75 \mathrm{GHz}$ & $14.48 \mathrm{~mm} \times 28.74 \mathrm{~mm} \times 0.8 \mathrm{~mm}$ \\
{$[23]$} & 2.88 to $13.71 \mathrm{GHz}$ & $36 \mathrm{~mm} \times 48 \mathrm{~mm} \times 01 \mathrm{~mm}$ \\
{$[24]$} & 2.45 to $17.9 \mathrm{GHz}$ & $36 \mathrm{~mm} \times 30 \mathrm{~mm} \times 1.5 \mathrm{~mm}$ \\
This paper & 3.1 to $20 \mathrm{GHz}$ & $22 \mathrm{~mm} \times 13 \mathrm{~mm} \times 1.5 \mathrm{~mm}$ \\
\hline
\end{tabular}

dimensions of the antenna are given in Table 2. The proposed antenna consists of a polygon radiating patch and a polygon ground. The modification is done in microstrip feed line for improving impedance matching.

\section{Results}

3.1. Bandwidth Enhancement of UWB Antenna. First a reference miniaturized UWB antenna has been designed and simulated which shows that operating bandwidth ranges from 3.1 to $10.6 \mathrm{GHz}$ as shown in Figure 2(a). Simulation is performed using CST Microwave Studio Suite. The surface of the partial ground plane is modified to increase the electrical path length which in turn enhances the impedance bandwidth without any cost of size. The antenna is then simulated and measured which shows that it covers the overall UWB band along with bandwidth enhancement from 3.1 to $20.0 \mathrm{GHz}$. Agilent E8364B network analyzer is used to obtain measured results. The simulated and measured results agree well as shown in Figure 2(b). The simulated and measured bandwidth almost ranges from 3.1 to $20.0 \mathrm{GHz}$. The discrepancy is mainly due to connector losses and handwelding inaccuracy. The designed antenna has a small size of $22 \times 13 \times 1.5 \mathrm{~mm}^{3}$ and the impedance bandwidth of the designed antenna is higher than the UWB antennas reported in the literature.

\subsection{Proposed Miniaturized UWB Antenna with Triple Band} Rejection. The proposed triple band-notched UWB antenna is presented in this section. The miniaturized antenna designed has the flexibility to notch the interfering bands because the band dispensation is achieved without using slot resonators or strips. Also most of the proposed antennas 
TABLE 2: Dimensions of the proposed antenna.

\begin{tabular}{lcccccccc}
\hline$L_{\text {sub }}$ & $W_{\text {sub }}$ & $W_{s}$ & $L_{s}$ & $W_{1}$ & $W_{2}$ & $L_{1}$ & $L_{2}$ & $L_{3}$ \\
\hline $22 \mathrm{~mm}$ & $13 \mathrm{~mm}$ & $9.8 \mathrm{~mm}$ & $3.4 \mathrm{~mm}$ & $1.6 \mathrm{~mm}$ & $10.2 \mathrm{~mm}$ & $1.4 \mathrm{~mm}$ & $2.1 \mathrm{~mm}$ & $4.5 \mathrm{~mm}$ \\
\hline$L_{4}$ & $L_{5}$ & $L_{6}$ & $g_{1}$ & $g_{2}$ & $g_{3}$ & $R_{1}$ & $R_{2}$ & $R_{3}$ \\
\hline $6.5 \mathrm{~mm}$ & $5 \mathrm{~mm}$ & $2 \mathrm{~mm}$ & $4.2 \mathrm{~mm}$ & $1.2 \mathrm{~mm}$ & $0.7 \mathrm{~mm}$ & $5.3 \mathrm{~mm}$ & $3.3 \mathrm{~mm}$ & $2 \mathrm{~mm}$ \\
\hline
\end{tabular}

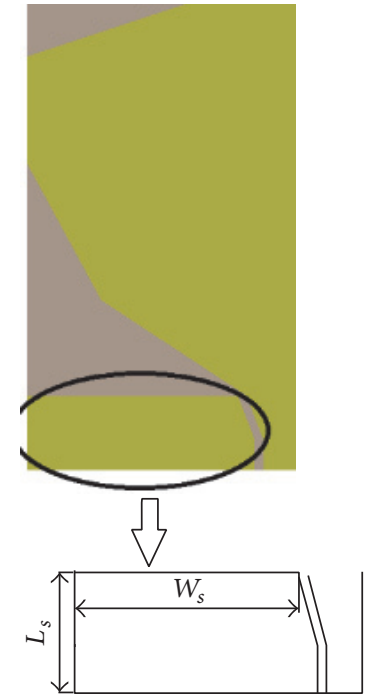

(a)

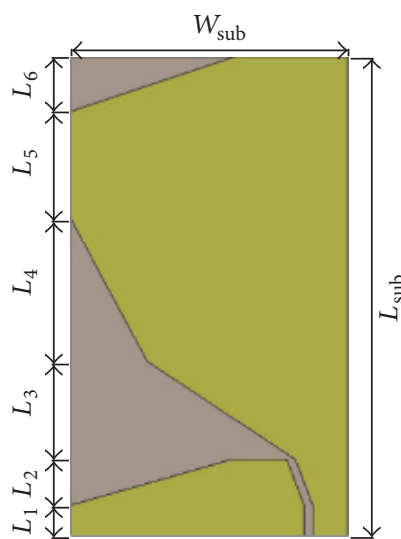

(b)
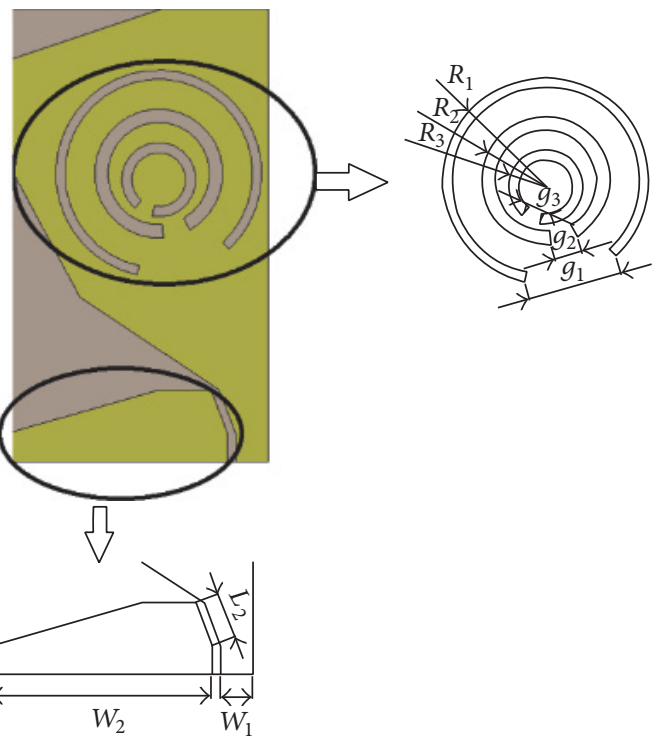

(c)

FIGURE 1: Geometry of the proposed antennas. (a) Miniaturized UWB antenna (3.1-10.6 GHz). (b) Miniaturized bandwidth enhanced UWB antenna (3.1-20 GHz). (c) Proposed miniaturized bandwidth enhanced triple notch UWB antenna.

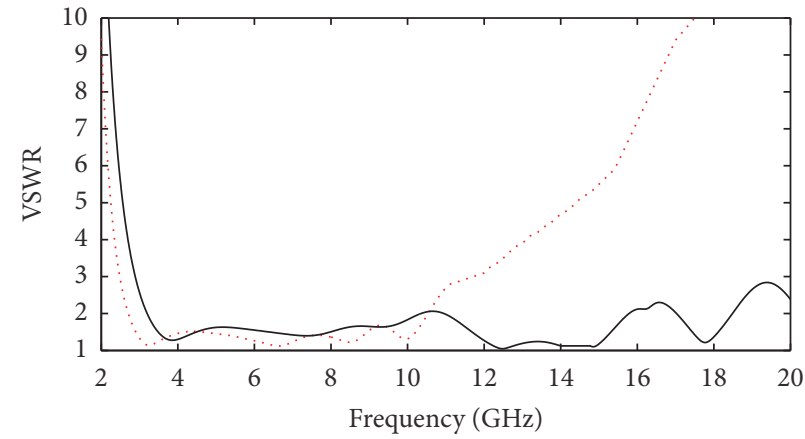

VSWR of UWB antenna without bandwidth enhancement — VSWR of UWB antenna with bandwidth enhancement

(a)

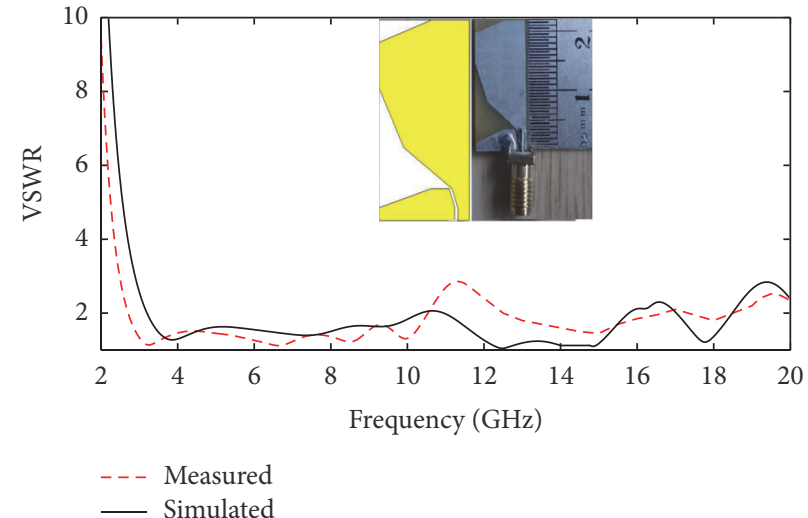

(b)

FIGURE 2: (a) VSWR of reference versus bandwidth enhanced UWB antenna. (b) Measured versus simulated VSWR of bandwidth enhanced UWB antenna. 


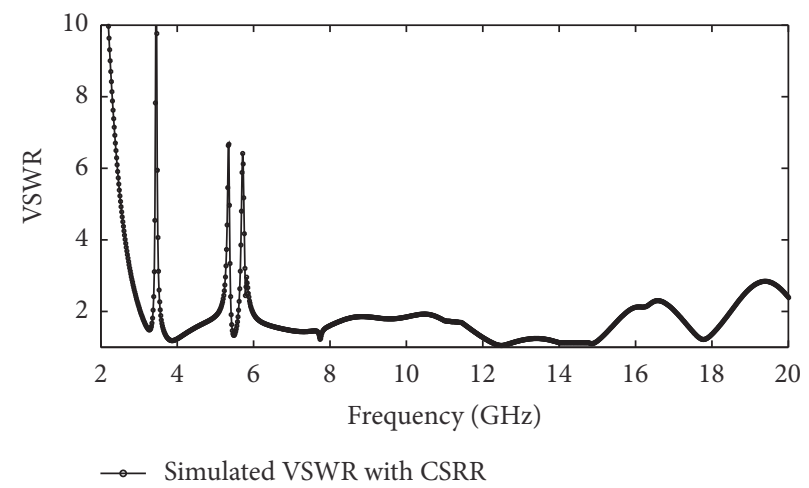

FIGURE 3: Simulated VSWR of the proposed miniaturized triple band-notched UWB antenna with enhanced bandwidth.

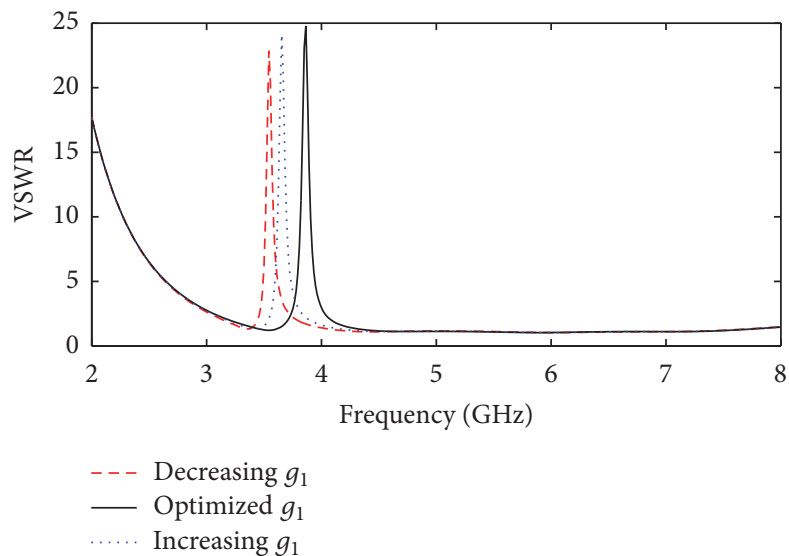

(a)

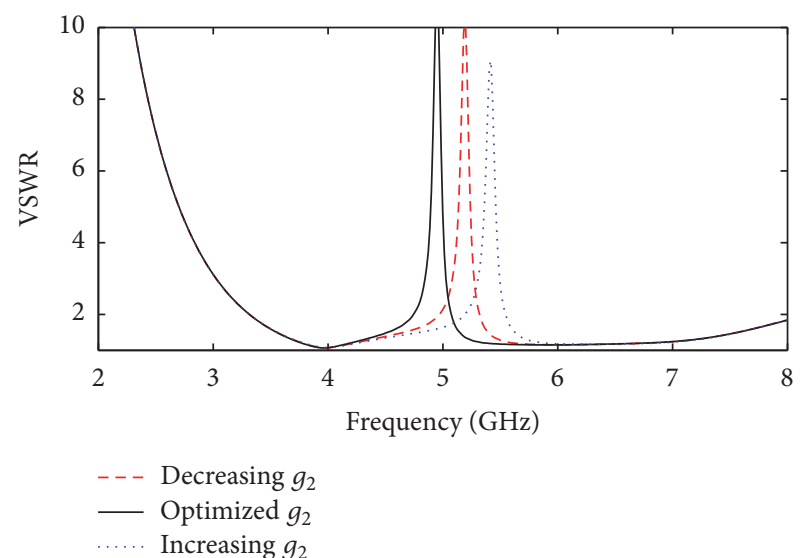

(b)

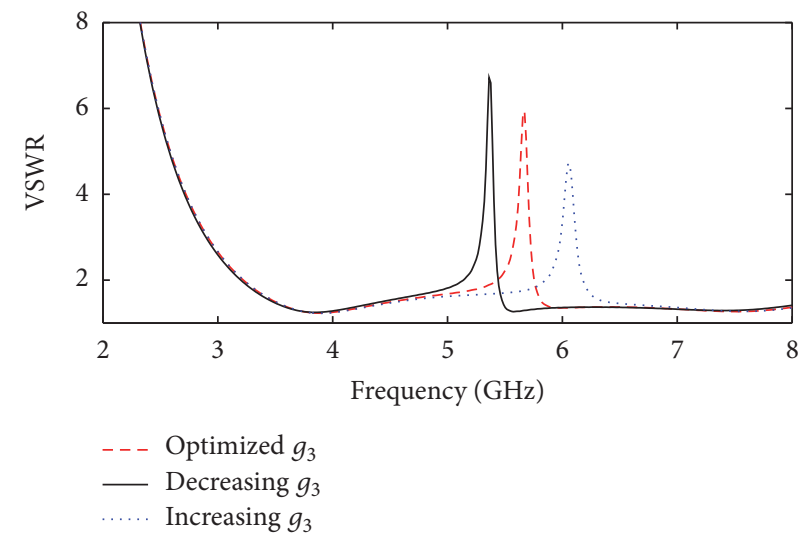

(c)

FIGURE 4: (a) Controlling mechanism for WiMAX band-notching. (b) Controlling mechanism for lower WLAN band-notching. (c) Controlling mechanism for upper WLAN band-notching.

reject the overall bandwidth from $5 \mathrm{GHz}$ to $6 \mathrm{GHz}$, which is not desired. The desired notched bands are $5.15-5.35 \mathrm{GHz}$ and $5.725-5.825 \mathrm{GHz}$ for lower and upper WLAN bands, respectively. Hence, any essential data may be lost resulting in the bad quality of signal and degradation of received information within the range of 5.35-5.725 GHz. Therefore, an efficient notching technique is still a difficult task to implement due to strong coupling between the adjacent frequencies.

The proposed triple band-notched UWB antenna is designed by introducing CSRR in the radiating patch. The lower WLAN $(5.15-5.35 \mathrm{GHz})$ and upper WLAN 


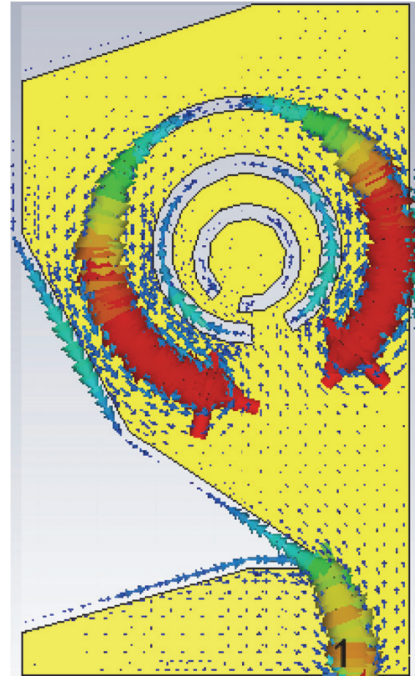

(a)

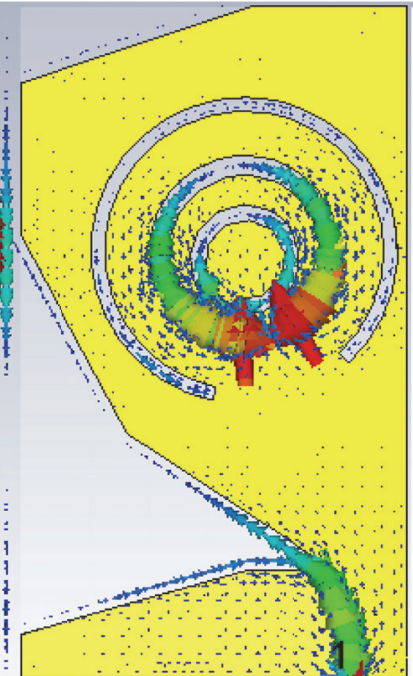

(b)

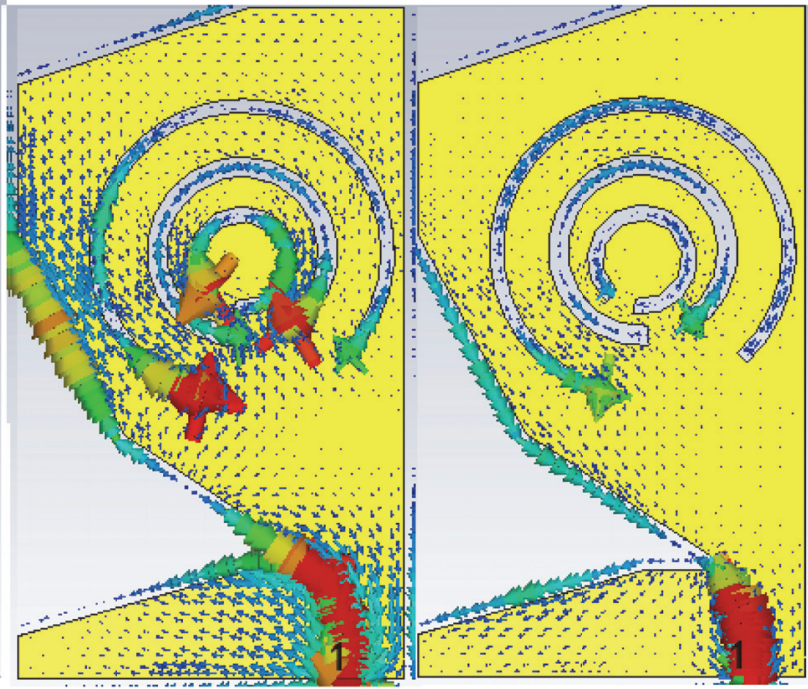

(c) (d)

Figure 5: Surface current distributions at (a) $3.5 \mathrm{GHz}$, (b) $5.25 \mathrm{GHz}$, (c) $5.75 \mathrm{GHz}$, and (d) $8.5 \mathrm{GHz}$.

(5.725-5.825 GHz) are notched using the two inner complementary split ring resonators while the WiMAX frequency band $(3.3-3.6 \mathrm{GHz})$ is notched using the outer complementary split ring resonator. The results are acceptable and show an improved triple notched behavior as shown in Figure 3. Also the VSWR plot clearly reveals that the notching is much sharp and the antenna will not lose any information while rejecting these interfering bands. The band-notch behavior makes the proposed antenna advantageous over the recently reported UWB antenna [8].

\subsection{Controlling Mechanism for Band-Notching. It is more} important for practical applications to control the notch bandwidths in order to obtain an effective band-notched UWB antenna. Therefore, the controlling technique of the developed band-notched antenna is studied in this section. It is clear from (4) that if we increase the radius of the ring, the notched bands will be shifted towards the lower frequencies and by decreasing the radius it will be shifted towards the higher frequencies. Figure 4 shows that by varying the radius of the rings the notch band can be shifted to a specific frequency band. The WiMAX, lower WLAN, and upper WLAN band can be controlled by increasing or decreasing $g_{1}, g_{2}$, and $g_{3}$ which are the gaps between the first, second, and third outer rings, respectively.

The stopband centered frequency corresponding to upper WLAN, lower WLAN, and WiMAX bands is approximately calculated by (1), (2), and (3), respectively

$$
\begin{aligned}
& f_{1}=\left(\frac{C}{2 \pi R_{1} \sqrt{\varepsilon_{r \mathrm{rff}}}}\right), \\
& f_{2}=\left(\frac{C}{2 \pi R_{2} \sqrt{\varepsilon_{\text {reff }}}}\right),
\end{aligned}
$$

$$
f_{3}=\left(\frac{C}{2 \pi R_{3} \sqrt{\varepsilon_{\text {reff }}}}\right) \text {, }
$$

where $\varepsilon_{r}$ is relative permittivity of the material, $C$ is speed of light in free space, $R_{1}$ is radius of the ring corresponding to upper WLAN band, $R_{2}$ is radius of the ring corresponding to lower WLAN band, and $R_{3}$ is radius of the ring corresponding to WiMAX band.

The above equations can be generalized for any notch frequency band given as

$$
f_{n}=\left(\frac{C}{2 \pi R_{i} \sqrt{\varepsilon_{\text {reff }}}}\right),
$$

where $n=1,2$, and 3 and $i=1,2$, and 3 .

3.4. Surface Current Distributions. Figure 5 shows the simulated current distributions on the surface of the proposed antenna at $3.5,5.25,5.75$, and $8.5 \mathrm{GHz}$. At $8.5 \mathrm{GHz}$ the current flows along the microstrip feed line, while low current densities flow around the slot. On the other hand, the surface current distribution on the antenna at 3.5, 5.25, and $5.75 \mathrm{GHz}$ is concentrated around the complementary split ring resonators (CSRR) which shows that complete electromagnetic energy is concentrated around the slots.

3.5. Radiation Pattern. The radiation pattern of the proposed antenna at different frequencies is shown in Figure 6. The plot shows that antenna has stable and omnidirectional radiation pattern. The main objective of these radiation patterns is to show that antenna radiates over a wide range of frequencies.

3.6. Antenna Gain. The antenna gain plot with and without CSRR is shown in Figure 7. The gain plot with notch shows that antenna gain is suppressed well in the WiMAX and WLAN bands. The minimum gain is $1.3 \mathrm{~dB}$ at WiMAX and 

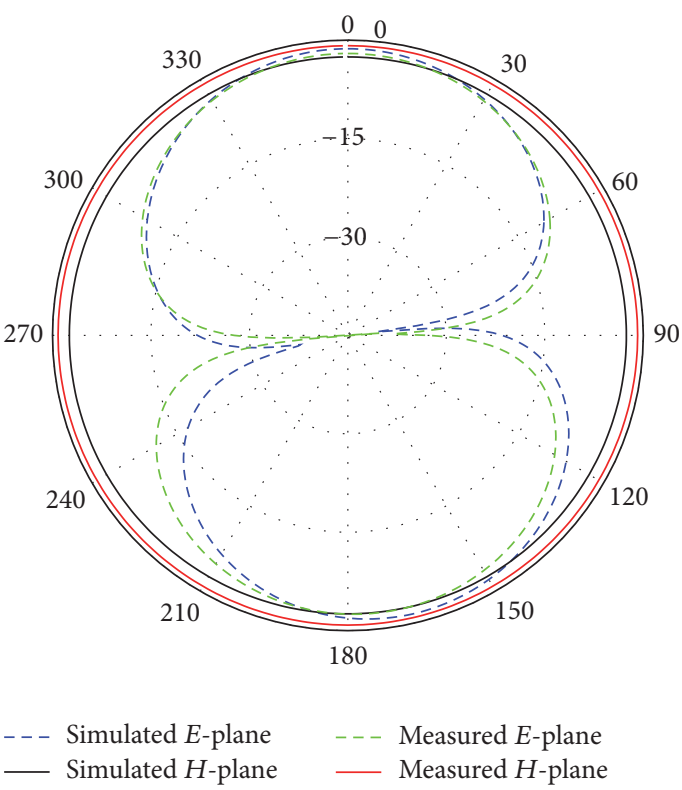

(a)

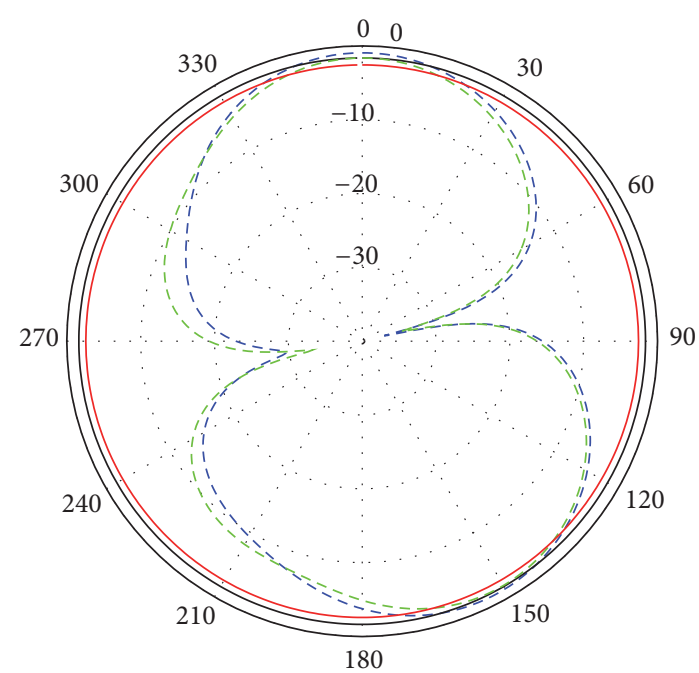

$\begin{array}{ll}\text { - - Simulated } E \text {-plane } & -- \text { Measured } E \text {-plane } \\ \text { _ Simulated } H \text {-plane } & \text { _ Measured } H \text {-plane }\end{array}$

(c)

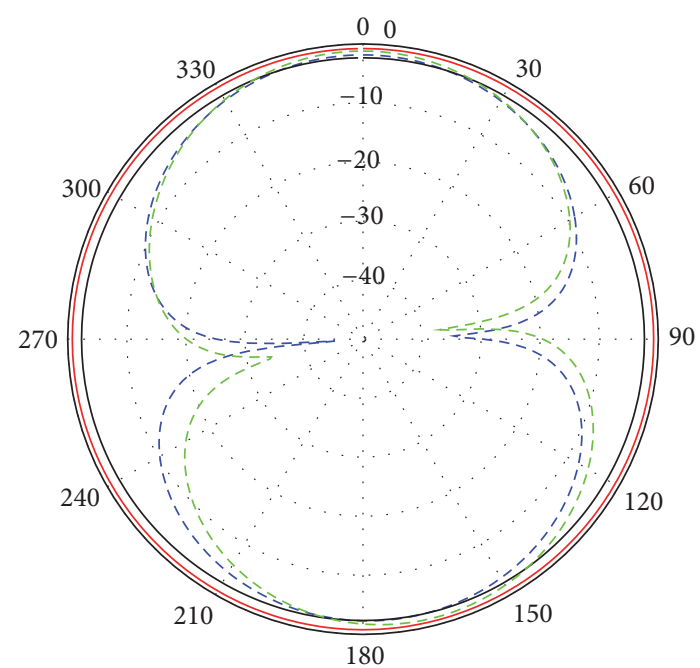

- - - Simulated E-plane _ - - Measured E-plane

Simulated $H$-plane

(b)

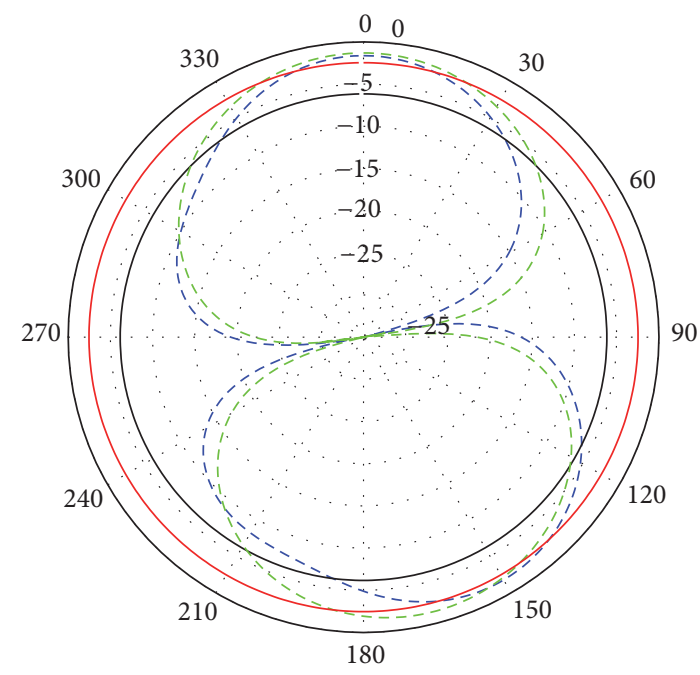

$\begin{array}{ll}\text { - - Simulated } E \text {-plane } & \text { - - } \text { Measured } E \text {-plane } \\ \text { - Simulated } H \text {-plane } \quad \text { Measured } H \text {-plane }\end{array}$

(d)

FIgURE 6: Radiation patterns at (a) $3.3 \mathrm{GHz}$, (b) $4.5 \mathrm{GHz}$, (c) $6.5 \mathrm{GHz}$, and (d) $9.5 \mathrm{GHz}$.

WLAN bands. The minimum gains indicate the destructive interference at those frequencies leading to band-notched creation. The maximum gain occurs at $11 \mathrm{GHz}$ which is $5.2 \mathrm{dBi}$.

\section{Conclusion}

In this paper, a proposed miniaturized tri-notched CPW fed ultra-wideband antenna along with bandwidth enhancement has been presented. First a reference miniaturized UWB antenna has been designed whose operating bandwidth ranges from 3.1 to $10.6 \mathrm{GHz}$. Then a modified miniaturized
UWB antenna is designed having $150 \%$ enhanced operating bandwidth from 3.1 to $20 \mathrm{GHz}$. The antenna is then further modified for tri-notch behavior along with bandwidth enhancement to make it more useful for UWB applications. The potential interference between the UWB system WiMAX and WLAN bands has been mitigated by introducing CSRR in the radiating patch. The results of the proposed antenna show stable gain except at the notch frequencies. The proposed antenna has a very compact size of $22 \times 13 \times 1.5 \mathrm{~mm}^{3}$ which makes it useful for portable UWB devices without causing electromagnetic interference. 


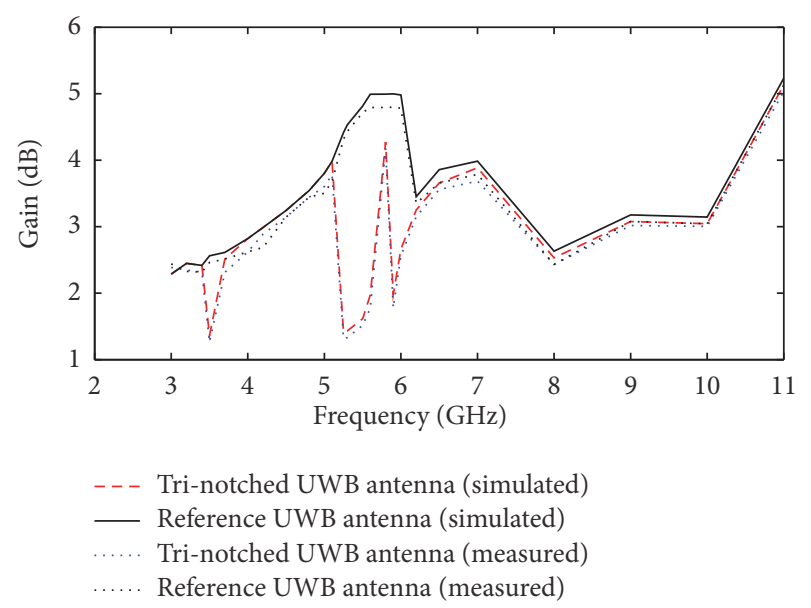

FIGURE 7: Gain of an antenna with and without notch.

\section{Competing Interests}

The author declares that there is no conflict of interests regarding the publication of this paper.

\section{References}

[1] M. Ojaroudi, G. Ghanbari, N. Ojaroudi, and C. Ghobadi, "Small square monopole antenna for UWB applications with variable frequency band-notch function," IEEE Antennas and Wireless Propagation Letters, vol. 8, pp. 1061-1064, 2009.

[2] S. J. Hong, J. W. Shin, H. Park, and J. H. Chol, "Analysis of the band-stop techniques for ultrawideband antenna," Microwave and Optical Technology Letters, vol. 49, no. 5, pp. 1058-1062, 2007.

[3] X. L. Bao and M. J. Ammann, "Printed band-rejection UWB antenna with $\mathrm{H}$-shaped slot," in Proceedings of the IEEE International Workshop on Antenna Technology (iWAT '07), pp. 319322, Cambridge, UK, March 2007.

[4] Q.-X. Chu and Y.-Y. Yang, "A compact ultrawideband antenna with $3.4 / 5.5 \mathrm{GHz}$ dual band-notched characteristics," IEEE Transactions on Antennas and Propagation, vol. 56, no. 12, pp. 3637-3644, 2008.

[5] Y. Zhang, W. Hong, C. Yu, Z.-Q. Kuai, Y.-D. Don, and J.-Y. Zhou, "Planar ultrawideband antennas with multiple notched bands based on etched slots on the patch and/or split ring resonators on the feed line," IEEE Transactions on Antennas and Propagation, vol. 56, no. 9, pp. 3063-3068, 2008.

[6] R. Zaker, C. Ghobadi, and J. Nourinia, "Bandwidth enhancement of novel compact single and dual band-notched printed monopole antenna with a pair of L-shaped slots," IEEE Transactions on Antennas and Propagation, vol. 57, no. 12, pp. 39783983, 2009.

[7] N. Ojaroudi and M. Ojaroudi, "Novel design of dual bandnotched monopole antenna with bandwidth enhancement for UWB applications," IEEE Antennas and Wireless Propagation Letters, vol. 12, pp. 698-701, 2013.

[8] N. Ojaroudi, "Compact UWB monopole antenna with enhanced bandwidth using rotated L-shaped slots and parasitic structures," Microwave and Optical Technology Letters, vol. 56, no. 1, pp. 175-178, 2014.
[9] G. Shrikanth Reddy, S. K. Mishra, S. Kharche, and J. Mukherjee, "High gain and low cross-polar compact printed elliptical monopole uwb antenna loaded with partial ground and parasitic patches," Progress In Electromagnetics Research B, no. 43, pp. 151-167, 2012.

[10] R. Azim and M. T. Islam, "Compact planar UWB antenna with band notch characteristics for WLAN and DSRC," Progress in Electromagnetics Research, vol. 133, pp. 391-406, 2013.

[11] J. Liu, K. P. Eselle, and S. S. Zhong, "A printed extremely wideband antenna for multi-band wireless systems," in Proceedings of the Antennas Propagation Society Symposium, Toronto, Canada, July 2010.

[12] M. N. Srifi, S. K. Podilchak, M. Essaaidi, and Y. M. M. Antar, "Compact disc monopole antennas for current and future ultrawideband (UWB) applications," IEEE Transactions on Antennas and Propagation, vol. 59, no. 12, pp. 4470-4480, 2011.

[13] M. U. Rahman, "Compact fractal based UWB band notch antenna," International Journal of Computer and Communication System Engineering, vol. 2, pp. 676-681, 2015.

[14] C.-Y. D. Sim, W.-T. Chung, and C.-H. Lee, "Compact slot antenna for UWB applications," IEEE Antennas and Wireless Propagation Letters, vol. 9, pp. 63-66, 2010.

[15] S. Lin, J. Wang, Y. Deng, and G. Zhang, "A new compact ultra-wideband balun for printed balanced antennas," Journal of Electromagnetic Waves and Applications, vol. 29, no. 12, pp. 1570-1579, 2015.

[16] C. Yoon, W.-J. Lee, W.-S. Kim, H.-C. Lee, and H.-D. Park, "Compact band-notched ultra-wideband printed antenna using inverted L-slit," Microwave and Optical Technology Letters, vol. 54, no. 1, pp. 143-144, 2012.

[17] C. Wang, Z.-H. Yan, B. Li, and P. Xu, "A dual band-notched UWB printed antenna with C-shaped and U-shaped slots," Microwave and Optical Technology Letters, vol. 54, no. 6, pp. 1450-1452, 2012.

[18] M. Ojaroudi and N. Ojaroudi, "Ultra-wideband small rectangular slot antenna with variable band-stop function," IEEE Transactions on Antennas and Propagation, vol. 8, pp. 1061-1064, 2009.

[19] Y. Yin and J. S. Hong, "UWB band-notched adjustable antenna using concentric split-ring slots structure," Frequenz, vol. 68, no. 9-10, pp. 433-439, 2014.

[20] S. M. Abbas, Y. Ranga, A. K. Verma, and K. P. Esselle, "A simple ultra wideband printed monopole antenna with high band rejection and wide radiation patterns," IEEE Transactions on Antennas and Propagation, vol. 62, no. 9, pp. 4816-4820, 2014.

[21] P. S. Bakariya, S. Dwari, and M. Sarkar, “Triple band notch UWB printed monopole antenna with enhanced bandwidth," AEUInternational Journal of Electronics and Communications, vol. 69, no. 1, pp. 26-30, 2015.

[22] X. Yin, C. Ruan, C. Ding, and J. Chu, "A planar u type monopole antenna for uwb applications," Progress in Electromagnetics Research Letters, vol. 2, pp. 1-10, 2008.

[23] T. Mandal and S. Das, "A coplanar waveguide fed hexagonal shape ultra wide band antenna with WiMAX and WLAN band rejection," Radioengineering Journal, vol. 23, no. 4, pp. 10771085, 2014.

[24] R. Kumar, N. Kushwaha, and R. V. S. Ram Krishna, "Design of ultra wideband hexagonal patch slot antenna for high-gain wireless applications," Journal of Electromagnetic Waves and Applications, vol. 28, no. 16, pp. 2034-2048, 2014. 


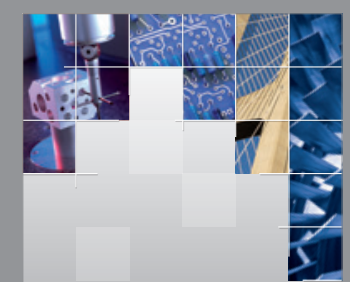

\section{Enfincering}
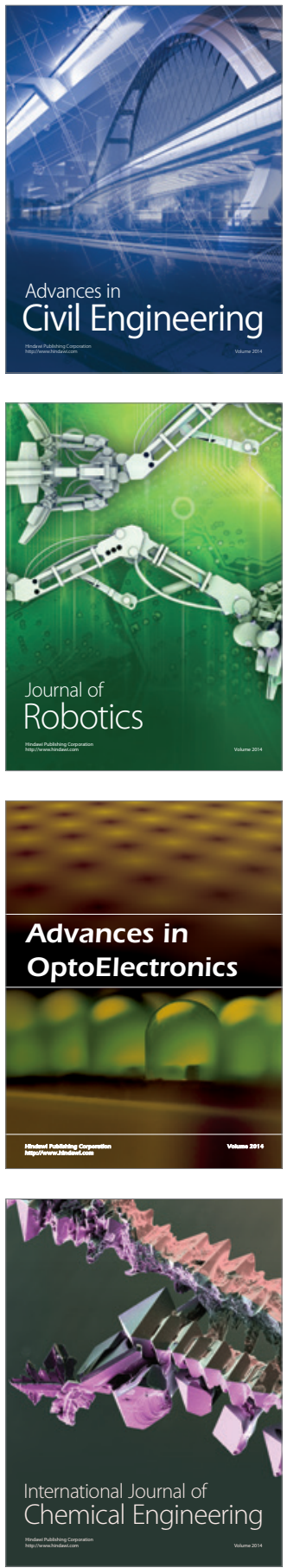

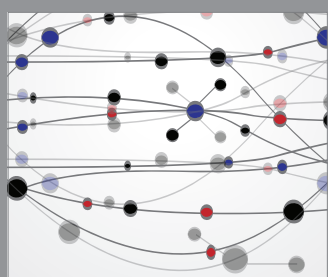

The Scientific World Journal

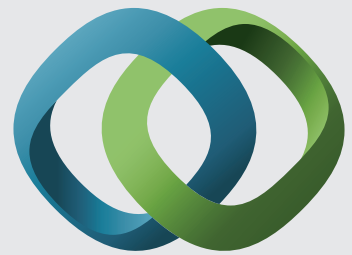

\section{Hindawi}

Submit your manuscripts at

http://www.hindawi.com
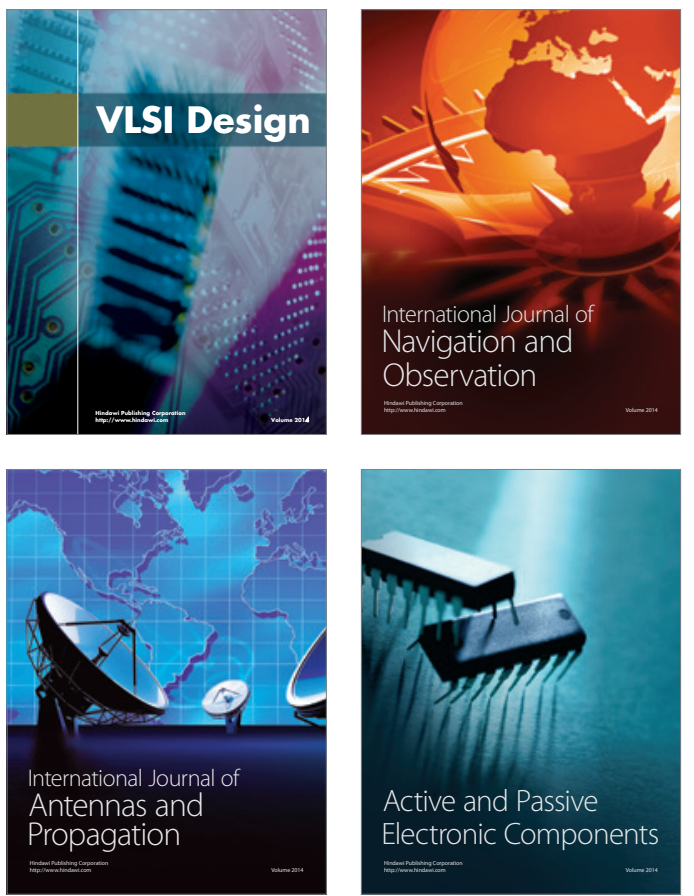
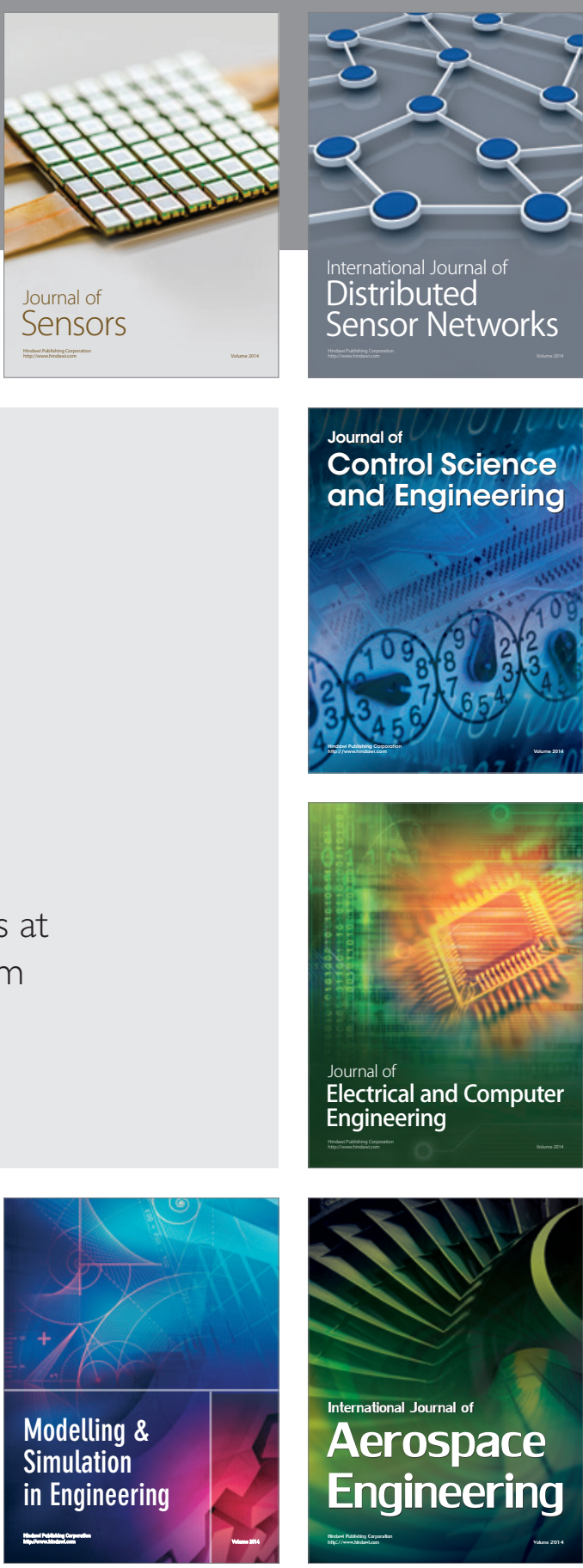

International Journal of

Distributed

Sensor Networks

Journal of

Control Science

and Engineering
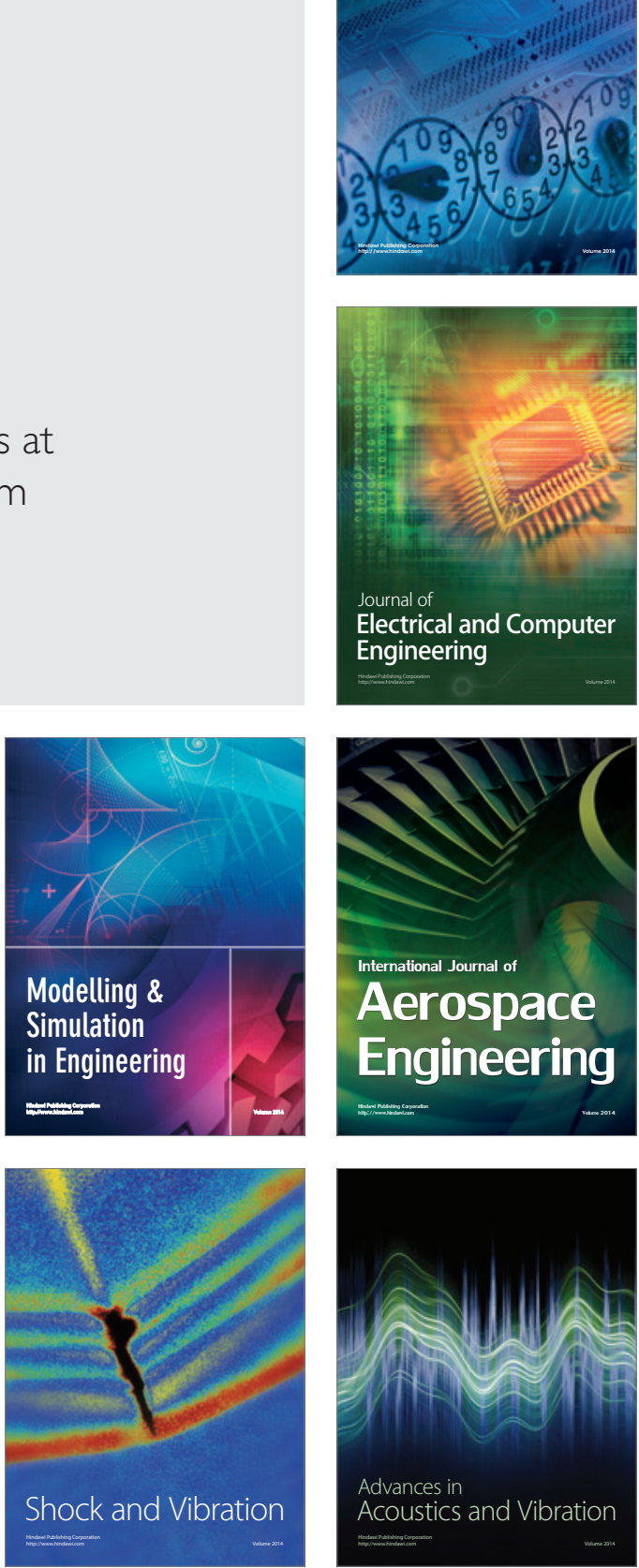